\title{
Study on the Construction of Medical College Discipline Echelon in Heilongjiang Province
}

\author{
Changfang Lu \\ Qiqihar Medical University, Qiqihar City, Heilongjiang Province, 161006, China
}

Keywords: Medical college and universities, Discipline echelon, Talent training, Construction model

\begin{abstract}
In the development of higher medical colleges, the role of discipline construction is becoming increasingly apparent. Discipline construction has become a fundamental task of medical colleges and universities as it carries the responsibilities and missions of medical colleges and universities, such as training medical talents, improving medical science and technology and improving people's health. Discipline construction is the fundamental task of medical colleges and universities, and it is of great significance to promote the development of medical colleges and universities. With the rapid development of higher medical education in China, the connotation and mode of discipline construction are constantly changing. Based on the author's study and practical experience, this paper first analyzed the connotation and significance of discipline echelon construction in medical colleges and universities, and then, according to the specific situation of Heilongjiang Province, it put forward the countermeasures of discipline echelon construction in medical colleges and universities. This paper is of great theoretical and practical significance for promoting the comprehensive, coordinated and sustainable development of medical colleges and universities.
\end{abstract}

\section{Introduction}

With the in-depth development of the teaching reform of higher medical education and the introduction of the new national policy, the construction, perfection and management of the subject system of higher medical institutions are of great concern to the theoretical research and practice workers of medical colleges and universities. Some problems include how to update the management model, pay attention to the development law of medical science, pay attention to the development trend of the discipline itself, make the discipline construction plan well and how to speed up the course of the discipline construction, are the fundamental tasks of the discipline construction and also the focuses of attention of the industry. This study took the management mode of discipline construction in medical colleges and universities as the research object, and probed into the evolvement course and realistic situation of the discipline construction management model in medical colleges and universities. Moreover, this paper analyzed the existing problems and put forward countermeasures to provide reference for the construction of discipline construction in higher medical colleges.

\section{Connotation and Significance of Discipline Echelon Construction in Medical Colleges and Universities}

Discipline is a collection of cognitive objects based on cognition and time. It is a relatively independent knowledge system and a specific category formed by scientific development. It is the name of academic classification and also is the basis for setting up teaching subjects. The discipline carries the task of training talents and accomplishes a great deal of scientific research at the same time, and the construction of echelon of discipline talents plays a leading role in improving the level of teachers and the quality of education and teaching. Discipline construction can be simply understood as the development of a discipline or a discipline of construction, which is based on the reality of a discipline. According to the law of scientific development, the trend of the development 
of the discipline and the needs of social development, it is the process of carrying out a series of practical activities to promote the development of the discipline, and to make the discipline level reach the established goal. The concrete construction content includes the teacher troop, the talented person training, the scientific research, the environment and the condition, the management level and so on. The level of discipline construction is a symbol of the status of a university, which determines the level of education and scientific research. Discipline construction is realized through the establishment of discipline system, the construction of talent echelon and other hardware and software conditions, which is closely related to the cultivation of talents and scientific research in schools. Discipline construction is an important carrier for universities to carry out the functions of talent training, scientific research and serving the society. Through vigorously carrying out discipline construction, the construction of teachers' ranks, the overall level of cultivation of talents and scientific research can be comprehensively improved. At present, the general medical colleges and universities have the objective reasons such as the lagging concept of running a school, the unscientific management model, the lack of regional advantages and the lack of funds to support them. The distribution of disciplines in medical colleges and universities is generally unbalanced, and some of the leading disciplines fail to play a leading role and fail to shoulder the responsibility of discipline construction. Moreover, the echelons are irrational and unmatched, and the research team is weak in strength. They lack the major scientific research projects and implementation platform which are carried out jointly between departments and colleges, and they fail to form a bright spot of cross-discipline, which is "concentrating the superior resources, making small efforts to make big efforts and embodying the characteristics".

\section{Countermeasures for the Construction of Disciplinary Echelon in Medical Colleges and Universities}

\subsection{Define the Scientific Orientation of Discipline Construction}

The construction of discipline should serve to train high-quality specialized medical personnel, especially for the future first-line medical and health-care talents. We should pay attention to the coordination of basic research and applied research, and the research results should be applied to the optimization of teaching materials and the teaching of basic courses and specialized courses as soon as possible. We should open up the advantage resources of the discipline, especially to the undergraduate and master students, and let them enter the discipline laboratory, and participate in the subject research project and join the academic exchange activity. We must let the discipline's production, study and research platform serve in teaching, especially for the postgraduate training base's research environment and experimental conditions for undergraduate's practical ability training. Discipline construction should serve to raise the level of scientific and technological innovation. Discipline construction is the basis and driving force of scientific research, and scientific research is the premise and driving force of discipline construction. Medical colleges and universities should be based on existing disciplines and work hard on original innovation. In the scientific research activities with the medical discipline as the main body, we should actively plan, absorb the participation of other discipline resources in the school, and build a cooperative platform. Moreover, we should design and undertake large projects in multi-disciplinary collective innovation, group scientific research, and form a interdisciplinary scientific research model such as transformational medicine, biomedicine, medical engineering and so on. We should strengthen the construction of discipline platform, set up academic research institute (institute) or laboratory as the center, gather high level scientific research talents, and form scientific and technological innovation team. Discipline construction should serve for transformation and upgrading. During the 12th Five-Year Plan period, the construction of strategic emerging industries and the adjustment of industrial structure require the discipline of medical colleges to establish a dynamic balance mechanism adapted to the adjustment of regional industrial structure. From the analysis of regional industrial information, we can find out and summarize the macro trend of regional industrial structure adjustment, and carry on corresponding adjustment according with the discipline law. 


\subsection{Adhere to the Characteristic Development Strategy of Discipline}

At present, the competition of disciplines has basically been transferred from comparative advantage to competitive advantage, and the subject construction has changed from relying on exclusive resources and policy inclination to pursuing the discipline "standard and innovation", that is, characteristic development. The discipline of medical college is difficult to reach the existing stock and increment of subordinate colleges and universities, and the advantage of obtaining discipline resources is not outstanding compared with comprehensive university. Therefore, the discipline of medical colleges and universities can only rely on characteristic development. There are many ways to develop the characteristic development of discipline construction, such as "people do not but I have", "people have but I am excellent", "people are excellent but I am special" and so on. However, from the root of the analysis, the key to the construction of the discipline is "differential development" and "misplaced competition". In order to avoid blind construction, the characteristic construction firstly should make the cientific evaluation. In the comprehensive evaluation of disciplines, the professional evaluation of the expert group is the first aspect, and the most important thing is to evaluate the internal and external environment of disciplines. We can learn from the "SWOT" analysis method and make a thorough analysis of the strengths, weaknesses, opportunities and threats of schools and disciplines before making mature decisions. Secondly, in the process of implementing characteristic construction, differentiation and dislocation should be the main thinking of discipline characteristic construction. "Differential development" is to cultivate the "heterogeneous "character of the discipline and other universities in the same category, and expand and promote them rapidly." misplaced competition" is to find a development path different from the same discipline.

\subsection{Attach Great Importance to the Construction of Key Disciplines}

Strengthening the construction of key disciplines is the fundamental way out for the discipline construction in medical colleges and universities. The adjustment of the discipline layout, or the distinction between the emphasis and the non-emphasis of the discipline, is, in the final analysis, the allocation of academic and economic resources, and the "doing something and not doing something" in the course of discipline construction. At present, due to the lack of resources, the government is often distributed in a competitive way to reflect fairness. Because most schools cannot compete the national and provincial government resources with "211", "985" universities and even local comprehensive universities, medical colleges and universities only on the basis of existing disciplines and concentrate all the advantages of resources. Moreover, they can concentrate all the advantages of the resources, set the power of the school to make key disciplines on the level and grade so that to firstly make a breakthrough. However, in the construction of key medical disciplines, they should attach importance to the integration of medical related disciplines and non-medical disciplines. First of all, they should help each other to carry out the secondary allocation of resources, and provide certain financial support to non-key medical disciplines. Secondly, they have to produce new discipline growth points through integration, so as to cultivate new features and occupy a place in the field of discipline. The direction of construction of key subjects in medical colleges and universities should be first-level disciplines. Many provinces have adjusted the direction of discipline construction. Zhejiang Province proposed that during the "12th Five-Year" period, 10 key disciplines should be built to connect with the national key disciplines. In order to obtain the iconic achievement in the discipline construction of medical colleges and universities, the goal should also be targeted at the national key disciplines.

\subsection{Building a More Open Atmosphere of Discipline Development}

First of all, they should open up discipline construction to affiliated hospitals. In recent years, with the deepening of the reform of the medical and health system, the development strategy of "revitalizing the hospital through science and education" has been widely used in hospitals. As the core content of hospital development, the construction of key medical disciplines has been attached importance to by each hospital itself. At the same time, in the evaluation of the grade hospital, the 
hospital also has a strong need to build a key discipline. Medical colleges and universities should actively consider this kind of reality and need in discipline construction, strengthen the connection between medical discipline construction and medical clinical practice by absorbing the power of affiliated hospitals to participate in discipline construction. Through this kind of connection, we can make full use of the leaders and practice platforms of departments and departments in hospitals, and further enrich the construction of discipline talents and platforms.

Secondly, they will open discipline to the international community. This is the main form of discipline that creates an open atmosphere. The first is to use all kinds of high-level talents at all levels to introduce the project, and actively introduce high-level discipline leaders to the international community. Secondly, it is necessary to make good use of the convenience of international communication and improve the effect of two-way communication of the discipline echelons, and attach great importance to the "going out" in the construction of the discipline echelons. Through "going out", we can improve the international field of vision of the discipline group, renew the concept of the subject and improve the management level. Third, they need to strengthen high-level cooperation in running schools, focus on strengthening cooperation with famous universities in the world, strong disciplines in foreign universities and similar high level universities, further expand doctoral and postgraduate communication scale, expand communication channels and enrich communication forms. Fourth, they should make good use of international scientific research project cooperation and academic exchange activities, advance the internationalization discipline platform construction. Medical colleges and universities should take advantage of the influence of dominant disciplines to actively host or host international academic conferences, encourage teachers to participate in international academic conferences with important influence, and support the active participation of disciplines in international cooperative research projects and apply for scientific research projects from international organizations and other countries, so as to promote the establishment of collaborative platforms between disciplines and foreign dominant disciplines. Moreover, to do that, they can attach the goal of working with foreign government departments, academia and industry departments to build the base of production, research and research, and try to build a laboratory and research institute with foreign universities and disciplines.

\section{Acknowledgements}

Rource: The Humanities Project of Heilongjiang Provincial Education Department.

Name: Study on the Construction of Discipline Echelon in Heilongjiang Medical Colleges.

Number: 2016-KYYWF-0896.

\section{References}

[1] Ling Wei. Strengthening the Construction of Talent Echelon and Training the Key Clinical Talents [J]. Economist, 2017, (09): 249-250.

[2] Jiang Hong. Exploration on the Construction of Echelon of Leading Talents [J]. China High and New Technology Development Zone is 15: 232.

[3] Liang Jiahui. Research on the Construction of Scientific Research Team in Applied Undergraduate Colleges [J]. Reform and Opening Up, 2016, (22):91-92.

[4] Gu Zhenyao. Strategic Thinking on Discipline Construction in Large-scale General Hospitals [J]. Summary of the Latest Medical Information in the World, 2016, (78):206.

[5] Liu Shuijuan. Strengthening the Construction of Discipline Echelon to Promote the Sustainable Development of Higher Vocational Colleges [J]. Joint Journal of Tianjin Vocational Colleges and Universities, 2013, (06):51-54.

[6] Liu Zengli. Constructing Discipline Echelon and Strengthening Talent Training is the Basic Strategy of Discipline Construction [J]. Chinese talents: 190-191.

[7] Wang Jian, Wang Haibao. Analysis of Talent Echelon Construction of Hospital Clinical Discipline [J]. Health Economic Research: 2010: 46-47. 